\title{
Smoking cessation in pregnant women with mental disorders: a cohort and nested qualitative study
}

\author{
LM Howard, ${ }^{\text {a,b }}$ D Bekele, ${ }^{a}$ M Rowe, ${ }^{a} J$ Demilew, ${ }^{b}$ S Bewley, ${ }^{b}$ TM Marteau ${ }^{c}$ \\ a PO31 Institute of Psychiatry, King's College London, London, UK ${ }^{b}$ Women's Health Academic Centre, King's Health Partners, St Thomas' \\ Hospital, London, UK ${ }^{\mathrm{c}}$ Psychology \& Genetics Research Group, Department of Psychology (at Guy's), Institute of Psychiatry, King's College \\ London, London, UK \\ Correspondence: LM Howard, PO31 Institute of Psychiatry, King's College London, De Crespigny Park, London, SE5 8AF, UK. \\ Email louise.howard@kcl.ac.uk
}

Accepted 25 September 2012. Published Online 21 November 2012.

Objective To investigate whether 1) pregnant smokers with mental disorders are less likely to accept referrals to smoking cessation services compared with pregnant smokers without disorders; 2) they experience specific barriers to smoking cessation.

Design Cohort study supplemented by cross-sectional survey and nested qualitative study.

Setting Three maternity services, London, UK.

Population Pregnant smokers with and without mental disorders.

Methods Case notes were examined on a cohort of 400 consecutive pregnant smokers; data were triangulated with routinely collected data on 845 pregnant smokers at two other sites; 27 pregnant smokers were interviewed using qualitative methods.

Main outcome measures Acceptance of referral to smoking cessation services; perceived barriers to quitting.

Results Pregnant smokers with a mental disorder recorded by midwives were one-quarter of the cohort $(97,23 \%)$, were more likely to accept referral to smoking cessation services (69\% versus $56 \%$, adjusted odds ratio $1.70,95 \%$ confidence interval $1.03-2.79$ ), but more likely to still smoke at delivery (69\% versus $56 \%$, adjusted odds ratio $2.63,95 \%$ confidence interval 1.41-4.92). Discussion about smoking was documented in $7.7 \%$ of subsequent antenatal visits in women with or without mental disorders. Pregnant smokers with diagnosed mental disorders reported that they and health practitioners did not prioritise smoking advice because of concern about adversely impacting mental health.

Conclusions Pregnant women with mental disorders appear more motivated, yet find it more difficult, to stop smoking. Prioritisation of mental health over smoking may therefore lead to increasing health inequality for this group. Research into effective smoking cessation interventions is required for those with mental disorders.

Keywords Mental disorders, pregnancy, smoking cessation.

Please cite this paper as: Howard L, Bekele D, Rowe M, Demilew J, Bewley S, Marteau TM. Smoking cessation in pregnant women with mental disorders: a cohort and nested qualitative study. BJOG 2013;120:362-370.

\section{Introduction}

Smoking is the leading preventable cause of fetal and childhood morbidity and mortality in high-income countries. ${ }^{1-3}$ Around $13 \%$ of pregnant women in the UK smoke throughout pregnancy, ${ }^{4}$ with similar rates in the USA. ${ }^{5}$ Smoking in women of childbearing age is rising in low-income to middle-income countries, with a predicted prevalence of $20 \%$ by $2025,{ }^{6}$ so it is becoming an important cause of infant death globally.

Women are more likely to stop smoking during pregnancy than at other times ${ }^{7} ; 25-40 \%$ have already stopped by the antenatal booking appointment. ${ }^{8}$ Continued smoking in pregnancy is associated with social disadvantage, low income, low education level, mental disorders, domestic violence and low levels of support. ${ }^{9,10}$ In the UK, the social patterning of smoking throughout pregnancy is striking, with recent published self-report data varying between $3 \%$ and $30 \%$ in Westminster and Blackpool respectively. ${ }^{4}$ Similarly, socioeconomic disadvantage is strongly associated with antenatal depression, ${ }^{11,12}$ so it is unsurprising that almost $50 \%$ of pregnant smokers have depression or other common mental disorders. ${ }^{10}$

Smoking cessation programmes in pregnancy reduce the proportion of women who continue to smoke $\mathrm{e}^{13,14}$ and can impact on birth outcomes ${ }^{15-17}$ so referral from maternity 
services is emphasised as an important component of antenatal care in current guidelines. ${ }^{18}$ Although there is evidence that cessation rates can be significantly lower in people with mental disorders, ${ }^{19}$ there has been no research on how mental disorders in pregnancy modify the effectiveness of the current NHS pathway for smoking cessation interventions.

We therefore aimed to investigate whether pregnant women with mental disorders: a) are less likely to accept referrals to smoking cessation services, b) are less likely to stop smoking by delivery, and c) differ in their experiences of smoking, smoking cessation and smoking cessation services compared with pregnant women without mental disorders.

\section{Methods}

\section{Cohort study}

\section{Setting}

We extracted, as part of an audit of smoking cessation in maternity services locally, routinely collected data ('booking', antenatal visits, delivery) from 400 consecutive pregnant women who reported smoking at the time of their first 'booking' appointment between 1 January 2010 and 31 May 2011 at an inner city maternity service, a teaching hospital, serving a deprived, multi-ethnic inner city population in southeast London (5000 deliveries per year). Booking and delivery data were available electronically. Detailed clinical data on other antenatal visits were only available from the hand-held paper records. The maternity service operates an opt-out policy for referrals to NHS smoking cessation services as recommended by NICE guidelines (NICE 2010), i.e. all pregnant women who smoke at booking are informed that the midwife will send a referral to smoking cessation services, unless they object. Women who accept are then contacted by telephone by the local smoking cessation services to agree or decline a future appointment. In Southwark, the main borough covered by the service, smoking at delivery is reported as lower than the national average, 5 versus $13.4 \%$.

Data from booking visit (electronic records)

Data included sociodemographic information (including self-reported ethnicity; index of deprivation calculated from the woman's postcode using the English Indices of Deprivation $2010^{20}$ and categorised in deciles of deprivation, with $0-10 \%$ being the most deprived and 90 $100 \%$ the least;) substance abuse history; current mental disorder-defined as either Whooley positive in response to the two 'Whooley questions' routinely asked by midwives as recommended by $\mathrm{NICE}^{21}$ to identify women with possible depression (see Supplementary material, Appendix S1), or receiving current treatment from general practice or psychiatric services, (a yes to either Whooley question has good specificity $(>82 \%)$ and reasonable sensitivity $(>70 \%)$ for screening for depression ${ }^{22,23}$ although it has not been validated in pregnancy); past psychiatric history including diagnosis; obstetric history; smoking status (whether or not they smoke); acceptance of referral to smoking cessation services recorded by midwives. Data on contacts by local smoking cessation services and attendances were not routinely available.

Data from subsequent antenatal visits (maternity notes)

For each antenatal contact with maternity services, data were collected from the notes on gestational age; health professional seen; documentation relating to smoking, current smoking, quit attempts, attendance at smoking cessation services. Smoking at delivery was recorded electronically.

\section{Booking data from other sites}

To triangulate findings from the cohort study, and to establish whether the opt-in policy impacted on referral rates differentially for women with mental disorders, supplementary information was gathered from routinely collected electronic data on consecutive pregnant smokers from two other inner London maternity services that use an opt-in policy for referrals to NHS smoking cessation services, i.e. women are not routinely referred but are invited by midwives to consider referral. Data were available for demographic variables, the Whooley questions and current mental health at booking only. We calculated that a sample size of 400 in each group would be sufficient to detect a difference in smoking cessation referral rates from $15 \%$ in the pregnant women without mental disorders compared with 7.5\% in pregnant women with mental disorders, assuming a significance level $P=0.05$ (double-sided) at 90\% power.

\section{Data analysis}

Data were analysed using STATA v10.1. ${ }^{24}$ The $t$ tests and chisquare tests (or Fisher's exact test where cell $n<5$ ) were used to compare sociodemographic and clinical characteristics between women with and without a current mental health problem and to compare the characteristics of those who accepted and declined referral to smoking cessation services. Multivariate analyses using logistic regression were used to investigate predictors of acceptance of smoking cessation referral and smoking at delivery, including potential confounders that were found to be related to mental health status in the bivariate analysis at $P<0.1$. Women who had a fetal death were excluded from the analysis of smoking cessation because smoking at delivery was not recorded; characteristics of excluded women were compared with included women to assess bias. Finally, the relationship between mental health status and documented discussions about smoking at antenatal visits (midwives and obstetricians examined in separate models) was analysed using a multilevel 
logistic regression model that accounted for the clustering by individual women (using xtmelogit in STATA), including random intercepts in the model to account for the correlation within individual women.

\section{Qualitative interview study}

Population

Pregnant women with $(n=13)$ and without $(n=14)$ mental disorders who smoked during pregnancy receiving maternity care in southeast London.

\section{Procedure}

A purposive sample of English-speaking pregnant women who smoked when first pregnant were recruited both from local maternity and perinatal psychiatry services and invited for an interview about smoking cessation to investigate experiences from a range of women who: stopped smoking since becoming pregnant or continued after antenatal booking; attended or declined smoking cessation services; screened Whooley positive or negative for mental disorders at booking; did or did not have a mental disorder needing psychiatric care; and included a range of ages, ethnicities and severities of mental health disorders. Recruitment continued until saturation of themes had been achieved.

\section{Measures}

Semi-structured qualitative interviews were carried out after piloting. Women were interviewed with the Clinical Interview Schedule-Revised version (CIS-R, a 15-20 minutes structured interview) $)^{25}$ to obtain ICD-10 operationalised psychiatric diagnoses. Interviewees were given a $£ 15$ gift voucher as compensation for their time. Interviews were audio-taped and transcribed verbatim. For women under psychiatric care, clinical diagnoses were obtained from records with the women's agreement.

\begin{abstract}
Analysis
Data were analysed using framework analysis. ${ }^{26}$ Framework analysis involves identifying a thematic framework; charting (involving abstraction and synthesis of key themes); mapping and interpretation of the dataset as a whole. This paper reports only results that illuminate the quantitative cohort study findings.
\end{abstract}

\section{Results}

\section{Demographic and background data-cohort study}

The sociodemographic and clinical characteristics of participants are provided in Table 1 . One hundred and five (26.3\%) women were primiparous, and $73(18.3 \%)$ booked after 20 weeks of gestation. Sixty-two (15.5\%) said yes to one of the Whooley questions (35 [8.8\%] answering 'yes' to both questions), and $51(12.7 \%)$ women reported receiving current mental health treatment from a general practice or psychiatric service; so a total of $97(24.3 \%)$ women were classified as having 'current mental disorders'. Women with current mental disorders were significantly less likely to live with a partner, and were more likely to report substance abuse. There were no other significant differences between the two groups.

Psychiatric history and substance misuse details - cohort study Diagnosis was only recorded for some women: there were 83 (21\%) women who reported a history of diagnosed depression (including 12 previous postnatal depression), five $(1.3 \%)$ with schizophrenia, three $(0.8 \%)$ with bipolar disorder, one $(0.3 \%)$ with an eating disorder and $11(2.8 \%)$ women had a history of self-harm or overdose without a specified diagnosis. Only two women reported that they had had contact with psychiatric services in the previous 12 months, but $43(10.8 \%)$ had seen a psychiatrist previously and $15(3.8 \%)$ had a history of a psychiatric admission. Nineteen $(4.8 \%)$ women were taking psychotropic medication at booking; 12 (3\%) antidepressants, four (1\%) antipsychotics, one lithium and one valproate; medication was missing for one woman. Sixty-three (15.8\%) women reported some type of substance abuse (one missing data, one type of drug not recorded). Cannabis-only use was reported in almost two-thirds of substance misusers $(n=35 / 399$; $8.8 \%)$, poly-drug use was also common $(n=19 ; 4.8 \%)$ and small numbers of women reported alcohol use $>4$ units per week $(n=4 ; 1 \%)$, cocaine $(n=2 ; 0.5 \%)$, and crack use $(n=3 ; 0.8 \%)$.

\section{Outcomes}

\section{Smoking referral}

All women were told a referral to smoking cessation would be made unless they declined-237 (59.3\%) women accepted referral to smoking cessation services. Table 2 shows that there were no clinical or sociodemographic differences between women who did and those who did not accept referral, other than women with current mental disorders being significantly more likely to accept a smoking cessation referral (odds ratio [OR] 1.74, 95\% confidence interval [95\% CI] 1.07-2.84; after adjustment for substance misuse and living alone: adjusted OR [AOR] 1.70, 95\% CI 1.03-2.79).

\section{Smoking status at delivery}

Fourteen women $(3.5 \%)$ who had a second-trimester or third-trimester fetal death, and one women who had a termination for trisomy 21 were not included in this analysis because of a lack of smoking data at delivery. An additional $48(12 \%)$ women had no delivery data, suggesting that they had moved or delivered elsewhere. There were no significant sociodemographic, clinical or mental health differences in 
Table 1. Sociodemographic and clinical characteristics of pregnant smokers with $(n=303)$ and without $(n=97)$ mental health problems

\begin{tabular}{|c|c|c|c|c|c|c|c|}
\hline $\begin{array}{l}\text { Characteristic ( } n=400 \text { unless } \\
\text { otherwise noted) }\end{array}$ & $\begin{array}{l}\text { No mental } \\
\text { disorder* }\end{array}$ & $\begin{array}{c}\text { Mental } \\
\text { disorder* }\end{array}$ & Total & OR & $95 \% \mathrm{Cl}$ & $\begin{array}{c}\text { Test } \\
\text { statistic** }\end{array}$ & $P$ \\
\hline Mean age (years), mean (SD) & $27.1(6.6)$ & $27.5(6.6)$ & $27.2(0.3)$ & & & -0.05 & 0.62 \\
\hline \multicolumn{8}{|l|}{ Ethnicity $(n=385)$} \\
\hline White & $190(65.3)$ & $63(67.0)$ & $253(65.7)$ & & & & \\
\hline Non-white & $101(34.7)$ & $31(33.0)$ & $132(34.3)$ & 0.93 & $0.57-1.51$ & 0.94 & 0.76 \\
\hline \multicolumn{8}{|l|}{ Index of deprivation (centile) $(n=383)$} \\
\hline $0-10 \%$ & $20(6.9)$ & $8(8.6)$ & $28(7.3)$ & & & 1.17 & \\
\hline $10-20 \%$ & $112(38.6)$ & $40(43.0)$ & $152(39.7)$ & 0.89 & $0.36-2.18$ & & 0.80 \\
\hline $20-30 \%$ & $82(27.9)$ & $24(25.8)$ & $105(27.4)$ & 0.74 & $0.29-1.89$ & & 0.53 \\
\hline$>30 \%$ & $77(26.6)$ & $21(22.6)$ & $98(25.6)$ & 0.68 & $0.26-1.77$ & & 0.43 \\
\hline \multicolumn{8}{|l|}{ Marital status $(n=367)$} \\
\hline Not married & $239(86.0)$ & $79(88.8)$ & $318(86.7)$ & & & & \\
\hline Married & $39(14.0)$ & $10(11.2)$ & 49 (13.4) & 0.77 & $0.37-1.62$ & 0.45 & 0.50 \\
\hline \multicolumn{8}{|l|}{ Lives with } \\
\hline Alone/children & $68(22.4)$ & $35(36.1)$ & $103(25.8)$ & & & & \\
\hline Husband/partner & $153(50.5)$ & $32(33.0)$ & $185(46.3)$ & 0.40 & $0.23-0.71$ & & 0.00 \\
\hline Relatives/friends/other & $82(27.1)$ & $30(30.9)$ & $112(28.0)$ & 0.71 & $0.40-1.27$ & 10.57 & 0.25 \\
\hline Substance misuse $(n=399)$ & $39(12.9)$ & $24(25.0)$ & $63(15.8)$ & 2.26 & $1.27-4.00$ & 8.07 & 0.00 \\
\hline \multicolumn{8}{|l|}{ Gestation at booking } \\
\hline First trimester & $74(57.4)$ & $58(59.8)$ & $232(58.0)$ & & & & \\
\hline Second/third trimester & $129(42.6)$ & $39(40.2)$ & $168(42.0)$ & 0.91 & $0.57-1.44$ & 0.17 & 0.68 \\
\hline \multicolumn{8}{|l|}{ Obstetric history } \\
\hline Previous perinatal death $(n=392)^{* * *}$ & $4(1.4)$ & $2(2.1)$ & $6(1.5)$ & & & & 0.64 \\
\hline \multicolumn{8}{|l|}{ Obstetric outcome } \\
\hline Gestation age $(n=334)$ & $39.0(1.71)$ & $38.3(3.47)$ & $38.8(2.26)$ & & & 2.48 & 0.01 \\
\hline Birthweight, mean (SD) $(n=329)$ & $3096.3(5,245)$ & 2,955 (711) & $3,063(575)$ & & & 1.90 & 0.06 \\
\hline Perinatal death $(n=352)$ & $8(3.0)$ & $6(6.1)$ & $14(4.0)$ & 2.46 & $0.83-7.30$ & 2.79 & 0.10 \\
\hline
\end{tabular}

those women with and without smoking at delivery data, other than a significantly higher rate of previous perinatal death in those without delivery data (see Supplementary material, Table S1).

Table 3 shows the sociodemographic and clinical differences in women who reported smoking or not smoking at delivery. White women were significantly less likely to have stopped smoking. Women with mental disorders at booking were significantly more likely to still be smoking than women without disorders (OR 2.60, 95\% CI 1.42-4.75; adjusted for ethnicity: AOR 2.63, 95\% CI 1.414.92).

Discussions of smoking at antenatal visits

Of the 2393 documented antenatal visits after booking, 324 (13.5\%) involved obstetricians (120 consultants, 204 trainees) and 1836 (76.7\%) involved midwives. The remaining 233 (9.7\%) visits were conducted by other practitioners including general practitioners and substance misuse specialists. Discussions of smoking were recorded for 141 (7.7\%) midwife visits, and 25 (7.5\%) obstetric visits. There was no difference in recorded discussions of smoking in women with or without current mental disorders by midwives (OR 1.39, 95\% CI $0.74-2.6$ ) or obstetricians (OR $0.51,95 \%$ CI $0.16-$ $1.60)$.

\section{Cross-sectional routinely collected data}

Of the 845 consecutive pregnant smokers (mean age 27.8 years, SD 6.2; $39 \%$ non-white) from two inner city maternity services with opt-in smoking cessation policies and routine data available electronically from 2011, 112 (13.3\%) had a current diagnosis of a mental disorder recorded, and $111(13.1 \%)$ were Whooley positive. One hundred and seventy-five $(21 \%)$ women had a current diagnosis or were Whooley positive and were categorised as having a 'current mental disorder'. There were 453 (53.6\%) records of smoking cessation referral offers that were declined by the majority, with only 189 (22.4\%) referrals made. Women with a current mental disorder were more likely to accept referral $(49 \% ; 51 / 104)$ than women without $(39.5 \% ; 138 / 349)$ (OR 1.47, 95\% CI 0.95-2.29; adjusted for ethnicity: AOR 1.62, 95\% CI 1.03-2.54). 
Howard et al.

Table 2. Characteristics of women accepting $(n=237)$ and declining $(n=163)$ referral

\begin{tabular}{|c|c|c|c|c|c|c|c|}
\hline Characteristic & Declined referral* & Accepted referral* & Total & OR & $95 \% \mathrm{Cl}$ & Test statistic** & $P$ \\
\hline Mental health problem & $30(18.4)$ & $67(28.3)$ & $97(24.3)$ & 1.75 & $1.07-2.84$ & 5.12 & 0.03 \\
\hline Age (years), mean (SD) & $27.1(7.0)$ & $27.1(6.4)$ & $27.0(6.6)$ & & & -0.09 & 0.93 \\
\hline \multicolumn{8}{|l|}{ Ethnicity $(n=385)$} \\
\hline White & $96(62.3)$ & $157(68.0)$ & $253(65.7)$ & 0.78 & $0.51-1.20$ & 1.30 & 0.26 \\
\hline Non-white & $58(37.7)$ & $74(32.0)$ & $132(34.3)$ & & & & \\
\hline \multicolumn{8}{|l|}{ Index of deprivation (percentile) $(n=383)$} \\
\hline $0-10 \%$ & $13(8.4)$ & $15(6.6)$ & $28(7.3)$ & 1.00 & $0.98-1.03$ & 0.52 & 0.67 \\
\hline $10-20 \%$ & $61(39.6)$ & $91(39.7)$ & $152(39.7)$ & & & & \\
\hline $20-30 \%$ & $41(26.6)$ & $64(28.0)$ & $105(27.4)$ & & & & \\
\hline$>30 \%$ & $39(25.3)$ & $59(25.8)$ & $98(25.6)$ & & & & \\
\hline \multicolumn{8}{|l|}{ Marital status $(n=367)$} \\
\hline Not married & $122(85.3)$ & $196(87.5)$ & $318(86.7)$ & 0.83 & $0.45-1.53$ & 0.36 & 0.55 \\
\hline Married & $21(14.7)$ & $28(12.5)$ & 49 (13.5) & & & & \\
\hline \multicolumn{8}{|l|}{ Lives with } \\
\hline Alone/children & $40(24.5)$ & $63(26.6)$ & $103(25.8)$ & 0.97 & $0.74-1.28$ & 0.32 & 0.85 \\
\hline Husband/partner & $78(47.9)$ & $107(45.2)$ & $185(46.3)$ & & & & \\
\hline Relatives/friends/other & $45(27.6)$ & $67(28.3)$ & $112(28.0)$ & & & & \\
\hline Substance misuse $(n=399)$ & $24(14.7)$ & $39(16.5)$ & $63(15.8)$ & 1.14 & $0.66-1.99$ & 0.23 & 0.63 \\
\hline \multicolumn{8}{|l|}{ Gestation at booking } \\
\hline First trimester & $86(52.8)$ & $146(61.6)$ & $232(58.0)$ & 0.70 & $0.46-1.04$ & 3.10 & 0.08 \\
\hline Second/third trimester & $77(47.2)$ & $91(38.4)$ & $168(42.0)$ & & & & \\
\hline \multicolumn{8}{|l|}{ Obstetric history } \\
\hline Previous perinatal death $(n=392) * * *$ & $3(1.9)$ & $3(1.3)$ & $6(1.5)$ & & & 0.23 & 0.64 \\
\hline
\end{tabular}

\section{Interview study}

\section{Population}

Fifty-three women were invited to participate and 27 consented to be interviewed, of whom 13 were in the second trimester, 13 in the third trimester and one was 4 weeks postnatal. Twenty-one women were recruited from antenatal services (two CIS-R diagnoses for severe depression, three moderate depressive disorder, three mild depressive disorder) and six from perinatal psychiatry services (two bipolar disorder, four recurrent depressive disorder). Participants' mean age was 29 years (SD 1.1, range 17-41), with ethnic variation (13 White, four Black African, six Black Caribbean, four Mixed/Other). The group contained 19 unemployed women, 18 with single marital status, with education status variation (five did not complete compulsory education, ten had obtained GCSEs or NVQs, ten had received a degree or above, two declined to state) and parity variation (nine women had no children, five had one child; six had two to five children); 14 pregnancies were unplanned. Most women reported that they had started smoking as teenagers with friends (three under 13 years old; three after 20 years old). Most reported smoking an average of ten cigarettes/day at the time of interview. Two (one each with bipolar and moderate depressive disorder) had stopped smoking in the second trimester.

\section{Perceived barriers to quitting}

Themes emerging from the interviews are shown in Table 4. Most were common to both groups of women and included the negative impact of the social and physical environment, and physical addiction. However, women with mental disorders described additional psychological addiction and a different type of relationship with smoking. Examples included: smoking used as a way of losing weight (eating disorder); mainly occurring when manic (bipolar disorder); was the only way to stay well despite the risks (depressive disorder); a quit attempt was feared as it could make the depression worse.

There was also some evidence of prioritisation of mental health over smoking by healthcare professionals:

"[obstetrician] was like-don't give up...we don't want you getting anxiety or stressed"... (woman with recurrent depression)

"One woman [referring to mental health social worker]... said-don't worry about it [smoking]"...(woman with depressive disorder) 
Table 3. Sociodemographic and clinical characteristics of those pregnant smokers who were or were not still smoking at delivery

\begin{tabular}{|c|c|c|c|c|c|c|c|}
\hline $\begin{array}{l}\text { Characteristic }(n=337 \text { unless } \\
\text { otherwise noted) }\end{array}$ & $\begin{array}{l}\text { Not smoking } \\
\text { at delivery* }\end{array}$ & $\begin{array}{c}\text { Smoking at } \\
\text { delivery* }\end{array}$ & Total & OR & $95 \% \mathrm{Cl}$ & Test statistic** & $P$ \\
\hline \multicolumn{8}{|l|}{ Current mental health problems } \\
\hline Yes & $16(13.33)$ & $62(28.6)$ & $78(23.2)$ & 2.6 & $1.42-4.75$ & 10.1 & 0.002 \\
\hline Age (years), mean (SD) & $27.1(6.7)$ & $27.1(6.5)$ & $27.0(6.6)$ & & & 0.02 & 0.98 \\
\hline \multicolumn{8}{|l|}{ Ethnicity $(n=325)$} \\
\hline White & $63(54.8)$ & $146(69.5)$ & $209(64.3)$ & 0.53 & $0.33-0.85$ & 7.03 & 0.008 \\
\hline Non-white & $52(45.2)$ & $64(30.5)$ & $116(35.7)$ & & & & \\
\hline \multicolumn{8}{|l|}{ Index of deprivation $(n=326)$} \\
\hline $0-10 \%$ & $9(7.6)$ & $16(7.7)$ & $25(7.7)$ & & & 1.54 & \\
\hline $10-20 \%$ & $44(37.3)$ & $89(42.8)$ & $133(40.8)$ & 1.13 & $0.46-2.78$ & & 0.78 \\
\hline $20-30 \%$ & $31(26.3)$ & $55(26.4)$ & $86(26.4)$ & 1.0 & $0.39-2.52$ & & 1.00 \\
\hline$>30 \%$ & $34(28.8)$ & $48(23.1)$ & $82(25.2)$ & 0.79 & $0.31-2.01$ & & 0.63 \\
\hline \multicolumn{8}{|l|}{ Marital status $(n=311)$} \\
\hline Not married & $95(84.1)$ & $176(88.9)$ & $271(87.1)$ & 0.66 & $0.34-1.29$ & 1.49 & 0.22 \\
\hline Married & $18(15.9)$ & $22(11.1)$ & $40(12.9)$ & & & & \\
\hline \multicolumn{8}{|l|}{ Lives with } \\
\hline Alone/children & $30(25.0)$ & $59(27.2)$ & $89(26.4)$ & & & & \\
\hline Husband/partner & $58(48.36)$ & $94(43.3)$ & $152(45.1)$ & 0.82 & $0.48-1.42$ & 0.78 & 0.49 \\
\hline Relatives/friends/other & $32(26.7)$ & $64(29.5)$ & $96(28.5)$ & 1.01 & $0.55-1.87$ & & 0.96 \\
\hline Substance misuse $(n=336)$ & $13(23.6)$ & $42(76.4)$ & $55(16.4)$ & 1.96 & $1.00-3.81$ & 4.00 & 0.49 \\
\hline \multicolumn{8}{|l|}{ Gestation at booking } \\
\hline First trimester & $69(57.5)$ & $119(54.8)$ & $188(55.8)$ & & & & \\
\hline Second/third trimester & $51(42.5)$ & $98(45.2)$ & $149(44.2)$ & 1.11 & $0.71-1.75$ & 0.22 & 0.64 \\
\hline \multicolumn{8}{|l|}{ Obstetric history $(n=336)$} \\
\hline Previous perinatal death $* * *$ & $1(0.83)$ & $2(0.93)$ & $3(1.8)$ & & & 0.008 & 1.00 \\
\hline
\end{tabular}

*Data are given as $n(\%)$ unless otherwise stated.

$* * t$ test or chi-square test unless otherwise stated.

$* * *$ Fisher's exact test.

Table 4. Barriers to smoking cessation in pregnancy

\begin{tabular}{|c|c|c|c|}
\hline Theme & Sub-theme & $\begin{array}{c}\text { No mental } \\
\text { disorder }(n=14)\end{array}$ & $\begin{array}{c}\text { Mental } \\
\text { disorder }(n=13)\end{array}$ \\
\hline \multirow[t]{3}{*}{ Social environment } & Family & $\sqrt{ }$ & $\sqrt{ }$ \\
\hline & Partner & $\sqrt{ }$ & $\sqrt{ }$ \\
\hline & Social network of peers & $\sqrt{ }$ & $\sqrt{ }$ \\
\hline Physical environment & Accessibility of cigarettes & $\sqrt{ }$ & $\sqrt{ }$ \\
\hline \multirow[t]{2}{*}{ Addiction } & Psychological & & $\sqrt{ }$ \\
\hline & Physical & $\sqrt{ }$ & $\sqrt{ }$ \\
\hline \multirow[t]{2}{*}{$\begin{array}{l}\text { Influence of mental illness on } \\
\text { smoking behaviour }\end{array}$} & $\begin{array}{l}\text { Smoking to help stay thin } \\
\text { (eating disorder) }\end{array}$ & & $\sqrt{ }$ \\
\hline & Smoking when acutely ill (manic) & & $\sqrt{ }$ \\
\hline $\begin{array}{l}\text { Smoking as way of coping with } \\
\text { stressful lives (helping emotional wellbeing) }\end{array}$ & & $\sqrt{ }$ & $\sqrt{ }$ \\
\hline \multirow[t]{4}{*}{ Services } & Judgemental & $\sqrt{ }$ & $\sqrt{ }$ \\
\hline & Lack of proactive follow up & $\sqrt{ }$ & $\sqrt{ }$ \\
\hline & Lack of continuity of care & $\sqrt{ }$ & $\sqrt{ }$ \\
\hline & Prioritisation of mental health over smoking & & $\sqrt{ }$ \\
\hline
\end{tabular}

$\sqrt{ }$, evidence of theme or subtheme from interviewees. 


\section{Discussion}

\section{Main findings}

Women with current mental disorders were more likely than other pregnant smokers to accept referral to smoking cessation services, whether maternity services used an optin or opt-out policy, suggesting that they are just as, if not more, motivated to stop. However, women with mental disorders were more likely to be still smoking at delivery, as has been reported elsewhere. ${ }^{9,10}$ The difficulties women with mental disorders have in stopping smoking may be related to limited encouragement and low rates of smoking discussions given by health professionals to all smokers beyond the initial opt-out offer ( $<8 \%$ recorded). Additional barriers may include giving a higher priority to mental health than smoking, found in both women and their maternity and mental health professionals in the qualitative study.

Many of the barriers to smoking cessation, such as the influence of the social and physical environment, smoking as an essential daily coping mechanism, and judgemental unsupportive professionals have been described elsewhere, including in pregnancy. ${ }^{27-29}$ However, the lower quit rates and the additional barriers described by pregnant women with mental disorders are consistent with research on people with mental disorders outside pregnancy; this may be because they are more heavily addicted. ${ }^{30}$ In addition, health professionals have not traditionally prioritised smoking cessation in people with mental disorders, possibly because of beliefs that people with mental disorders are less likely to want to stop smoking or that it will worsen the disorder. ${ }^{31,32}$ Negative perceptions and attitudes of healthcare professionals have been reported previously as barriers to treating nicotine addiction simultaneously with mental disorders. ${ }^{33}$ In addition, a current focus in the research literature (and on the internet) on the adverse in utero impact of 'stress' and mental symptoms on the baby ${ }^{34-36}$ may mistakenly lead women with mental disorders, and their healthcare professionals, to minimise the significant impact of smoking in pregnancy and prioritise mental health. This has been found in previous studies, which reported that smoking status is less likely to be recorded in medical records of pregnant women with mental illnesses. ${ }^{37,38}$

\section{Strengths and limitations}

Strengths of this study include: a substantial cohort of pregnant smokers using routinely collected data on mental health with verification of findings on smoking referral using routinely collected data from two other services; a large diverse sample in the nested qualitative component illuminating the findings; use of diagnostic instruments for mental disorders in the interview study. The main weakness in the study is the lack of data on the use of smoking cessation services after referral and the use of self-reported smoking status at delivery, which is likely to underestimate cigarette use. ${ }^{39,40}$ Other limitations include possible underdetection of mental disorders by midwives ${ }^{41,42}$ (though misclassification bias would have attenuated any significant differences), limited generalisability from inner London services, possible under-recording of discussions of smoking at antenatal visits and the impact of unmeasured confounders on smoking through pregnancy including the development of mental disorder later in pregnancy and other stressors such as congenital malformations and pregnancyrelated maternal complications.

\section{Implications}

No previous study to our knowledge has investigated how mental disorders modify the effectiveness of smoking cessation service delivery during pregnancy. Our findings highlight the need for smoking cessation services to feed back to maternity services whether or not individual women have attended their services and their outcomes, so that maternity professionals can proactively support and encourage women who are finding smoking cessation difficult. Pregnant smokers commonly have mental disorders, and this study suggests a mismatch between their motivation to stop smoking but low success; this may be partly because of concerns that smoking cessation may worsen the mental disorder with an adverse impact on the fetus as seen here in both women and professionals as a reason to continue to smoke. There have been few prospective studies of mental health in pregnancy in women who stop smoking compared with those who do not. However, there is evidence that smoking cessation in pregnancy is associated with decreased depressive symptoms. ${ }^{43}$ Without help for both their mental disorders and smoking, pregnant women with mental disorders will inevitably continue to have worse smoking and obstetric outcomes. ${ }^{37,44}$ This study highlights the need to develop more effective smoking cessation interventions for pregnant smokers with mental disorders.

It is plausible that modification of smoking cessation interventions or contemporaneous delivery of mental health interventions alongside a smoking cessation programme are needed to improve smoking, obstetric and mental health outcomes.

Recent systematic reviews have reported that smoking cessation interventions can be just as effective for people with severe mental illnesses and depression (who are being treated for both the mental illness and smoking) compared with the general population, ${ }^{45,46}$ though higher rates of abstinence can be achieved in people with depression when involving intensive psychosocial interventions as adjunct to treatment ${ }^{30}$ or cognitive behavioural therapy. ${ }^{47}$ One randomised controlled trial of integrated cognitive behavioural therapy during pregnancy-addressing depression, partner violence, smoking and environmental 
tobacco smoke exposure in high risk African-American women-reported that mothers in the intervention arm reduced their environmental exposure and were less likely to be smoking postpartum, although there was no impact on smoking rates during pregnancy (possibly related to high spontaneous quit rates in both intervention and control arms). ${ }^{48}$ The intervention also had a significant impact on very preterm birth and very low birthweight. ${ }^{49}$ Although the study needs replication it suggests that integrated interventions may be particularly beneficial, that is addressing the cluster of mental health and other associated problems, such as domestic violence, ${ }^{50}$ alongside smoking cessation.

Population level strategies that impact on environmental smoke exposure and accessibility to cigarettes, and that include education campaigns, are also important. There is evidence from the Sudden Infant Death Syndrome reduction campaign that such campaigns can reduce rates of antenatal smoking in women with severe mental disorders. ${ }^{51}$

\section{Conclusion}

Pregnant women with mental disorders appear more motivated, yet find it more difficult, to stop smoking. Further investigations of smoking cessation interventions for pregnant women with mental disorders are urgently needed. At the maternity service level, there is clearly unrealised potential for health professionals to improve their interactions regarding smoking when seeing pregnant women with mental disorders. Otherwise, the failure to overcome barriers to smoking cessation will continue to compound intergenerational health impacts and inequities for vulnerable and deprived women.

\section{Disclosure of interest}

LMH, JD, SB and TM received a grant from the Foundation for the Study of Infant Death to carry out this research; LMH is also supported by Tommys the Baby Charity and the National Institute for Health Research (NIHR) Mental Health Biomedical Research Centre at South London and Maudsley NHS Foundation Trust and King's College London. All authors have no non-financial interests that may be relevant to the submitted work. There are no other competing interests.

\section{Contribution to authorship}

The authors were involved as follows: LMH for conception, design, data acquisition and supervision, data analysis and interpretation, and drafting the article; DB and MR for design, data acquisition and analysis; JD for conception, data acquisition and interpretation of analysis; SB and TNM for conception, design, data interpretation and drafting of the article; all were involved in revision and final approval.

\section{Details of ethics approval}

The cohort study was part of an audit at King's College Hospital (ref. AP1130-01). The qualitative study and crosssectional survey using routinely collected data had ethical approval from the Joint South London and Maudsley and the Institute of Psychiatry NHS Research Ethics Committee (the Joint SLAM/IOP REC) (Ref. no 10/H0807/89); interview participants gave informed consent before taking part.

\section{Funding}

This work was funded by the Foundation for the Study of Infant Deaths.

\section{Acknowledgements}

We would like to thank the staff and women who helped us or participated in this study, Manpreet Dhillon and Helen Galley for data collection and Ulrike Neumann for help with statistical analysis.

\section{Supporting Information}

Additional Supporting Information may be found in the online version of this article at the publisher's web site:

Table S1. Characteristics of women with smoking data at delivery $(n=337)$ and without $(n=63)$.

Appendix S1. Whoolley questions asked by midwives at antenatal booking.

\section{References}

1 Flenady V, Koopmans L, Middleton P, Frøen JF, Smith GC, Gibbons K, et al. Major risk factors for stillbirth in high-income countries: a systematic review and meta-analysis. Lancet 2011;377:1331-40.

2 Hackshaw A, Rodeck C, Boniface S. Maternal smoking in pregnancy and birth defects: a systematic review based on 173687 malformed cases and 11.7 million controls. Hum Reprod Update 2011;17:589-604.

3 Royal College of Physicians. Passive smoking and children: a report of the Tobacco Advisory Group of the Royal College of Physicians. London: Royal College of Physicians, 2010.

4 NHS Information Centre for Health and Social Care. Statistics on women's smoking status at time of delivery: England, Quarter 3, 2012 www.ic.nhs.uk. Accessed October 2012.

5 U.S. Department of Health and Human Services HRaSAMaCHB. Women's Health USA 2010. Rockville, MD: US Department of Health and Human Services, 2010.

6 World Health Organisation. WHO report on the global TOBACCO epidemic.Geneva: WHO, 2008.

7 Cnattingius S. The epidemiology of smoking during pregnancy: smoking prevalence, maternal characteristics, and pregnancy outcomes. Nicotine Tob Res 2004;6:S125-40.

8 LeClere FB, Wilson JB. Smoking behaviour of recent mothers, 18 44 years of age, before and after pregnancy: United States, 1990. In: Statistics Va H, editor. Advance Data. Atlanta, GA: National Center for Health Statistics, Centre for Disease Control, 1997:11.

9 Dejin-Karlsson E, Hanson BS, Ostergren PO, Ranstam J, Isacsson SO, Sjoberg NO. Psychosocial resources and persistent smoking in early pregnancy-a population study of women in their first pregnancy in Sweden. J Epidemiol Community Health 1996;50:33-9. 
10 Goodwin R, Keyes K, Simuro N. Mental disorders and nicotine dependence among pregnant women in the United States. Obstet Gynecol 2007;109:875-83.

11 Bledsoe SE, Grote NK. Treating depression during pregnancy and the postpartum: a preliminary meta-analysis. Res Soc Work Pract 2006;16:109-20.

12 Lancaster CA, Gold KJ, Flynn HA, Yoo H, Marcus SM, Davis MM. Risk factors for depressive symptoms during pregnancy: a systematic review. Am J Obstet Gynecol 2010;202:5-14.

13 Ershoff DH, Quinn VP, Boyd NR, Stern J, Gregory M, Wirtschafter $D$. The Kaiser Permanente prenatal smoking-cessation trial: when more isn't better, what is enough? Am J Prev Med 1999;17: $161-8$.

14 Ockene J, Ma Y, Zapka J, Pbert L, Valentine Goins K, Stoddard A. Spontaneous cessation of smoking and alcohol use among lowincome pregnant women. Am J Prev Med 2002;23:150-9.

15 Aquilino ML, Goody CM, Lowe JB. WIC providers' perspectives on offering smoking cessation interventions. MCN Am J Matern Child Nurs 2003;28:326-32.

16 Lumley J, Chamberlain C, Dowswell T, Oliver S, Oakley L, Watson L. Interventions for promoting smoking cessation during pregnancy. Cochrane Database Syst Rev 2009;Issue 3:CD001055. DOI: 10.1002/ 14651858.CD001055.pub3.

17 Heil SH, Higgins ST, Bernstein IM, Solomon LJ, Rogers RE, Thomas CS, et al. Effects of voucher-based incentives on abstinence from cigarette smoking and fetal growth among pregnant women. Addiction 2008;103:1009-18.

18 NICE. How to stop smoking in pregnancy and following childbirth. NICE public health guidance 26: Quitting smoking in pregnancy and following childbirth. London: NICE, 2010.

19 Lasser K, Boyd JW, Woolhandler S, Himmelstein DU, McCormick D, Bor DH. Smoking and mental illness. JAMA 2000;284:2606-10.

20 Department for Communities and Local Government. English indices of deprivation 2010. [www.communities.gov.uk/publications/ corporate/statistics/indices2010]. Accessed 4 March 2012.

21 NICE. Antenatal and postnatal mental health: clinical management and service guidance. London: NICE, 2007.

22 Caughey AB, Rosenstein MG, Cheng YW, Ward C, Nicholson J. The risk of perinatal death stratified by gestational age and modified by maternal age. Am J Obstet Gynecol 2011;204:S73-4.

23 Arroll B, Khin N, Kerse N. Screening for depression in primary care with two verbally asked questions: cross sectional study. BMJ 2003;327:1144-6.

24 StataCorp.Statistics/data analysis Stata v10.1 Copyright 1984-2009.

25 Lewis G, Pelosi A, Araya R, Dunn G. Measuring Psychiatric Disorders in the community: a standardized assessment for use by law interviewers (CIS-R, Chile). Psychol Med 1992;22:465-86.

26 Bryman A, Burgess R, Ritchie J, Spencer L. Qualitative data analysis for applied policy research. In: Bryman A, Burgess R, editors. Analysing Qualitative Data. London: Routledge, 1994:173-94.

27 Hollingsworth LD. Child custody loss among women with persistent severe mental illness. Soc Work Res 2004;28:199-209.

28 Reitzel LR, Cromley EK, Li Y, Cao Y, Dela Mater R, Mazas CA, et al. The effect of tobacco outlet density and proximity on smoking cessation. Am J Public Health 2011;101:315-20.

29 Mantzari E, Vogt F, Marteau TM. The effectiveness of financial incentives for smoking cessation during pregnancy: is it from being paid or from the extra aid? BMC Pregnancy Childbirth 2012; $12: 24$.

30 Aubin HJ, Rollema H, Svensson TH, Winterer G. Smoking, quitting, and psychiatric disease: a review. Neurosci Biobehav Rev 2012;36:271-84.

31 Williams J, Ziedonis D. Addressing tobacco among individuals with a mental illness or an addiction. Addict Behav 2004;29:1067-83.
32 Williams JM. Eliminating tobacco use in mental health facilities. Patients' rights, public health, and policy issues. JAMA 2008;299:571-3.

33 McNally L, Oyefeso A, Annan J, Perryman K, Bloor R, Freeman S, et al. A survey of staff attitudes to smoking-related policy and intervention in psychiatric and general health care settings. I Public Health (Oxf) 2006;28:192-6.

34 Federenko IS, Wadhwa PD. Women's mental health during pregnancy influences fetal and infant developmental and health outcomes. CNS Spectr 2004;9:198-206.

35 Grote NK, Bridge JA, Gavin AR, Melville JL, lyengar S, Katon WJ. A meta-analysis of depression during pregnancy and the risk of preterm birth, low birth weight, and intrauterine growth restriction. Arch Gen Psychiatry 2010;67:1012-24.

36 Glover V. Prenatal stress and the origins of psychopathology: an evolutionary perspective. J Child Psychol Psychiatry 2011;52:356-67.

37 Howard L, Goss C, Leese M, Thorniroft G. Medical outcome of pregnancy in women with psycotic disorders and their infants in the first year after birth. Br J Psychiatry 2003;182:63-7.

38 Kelly R, Danielsen BH, Golding JM, Anders TF, Gilbert WM, Zatzick DF. Adequacy of prenatl care among women with psychiatric diagnoses giving birth in California in 1994 and 1995. Psychiatr Serv 1999:50:1584-90.

39 Russell T. Measurements for active cigarette smoke exposure in prevalence and cessation studies: why simply asking pregnant women isn't enough. Nicotine Tobacco Res 2004;6:141-51.

40 Shipton D. Reliability of self reported smoking status by pregnant women for estimating smoking prevalence: a retrospective, cross sectional study. Br Med J 2009;29:339.

41 Marcus S, Flynn H, Blow F, Barry KL. Depressive symptoms among pregnant women screened in obstetrics settings. J Womens Health 2003;12:373-80

42 Smith MV, Rosenheck RA, Cavaleri MA, Howell HB, Poschman K, Yonkers KA. Screening for and detection of depression, panic disorder, and PTSD in public-sector obstetric clinics. Psych Serv 2004; 55:407-14.

43 Munafo MR, Heron J, Araya R. Smoking patterns during pregnancy and postnatal period and depressive symptoms. Nicotine Tob Res 2008;10:1609-20.

44 Webb R, Abel K, Pickles A, Appleby L. Mortality in offspring of parents with psychotic disorders: a critical review and meta-analysis. Am J Psychiatry 2005; 162:1045-56.

45 Banham L, Gilbody S. Smoking cessation in severe mental illness: what works? Addiction 2010;105:1176-89.

46 Tsoi DT, Porwal M, Webster AC. Interventions for smoking cessation and reduction in individuals with schizophrenia. Cochrane Database Syst Rev 2010;Issue 6:CD007253. DOI: 10.1002/14651858. CD007253.pub2.

47 Haas AL, Munoz RF, Humfleet GL, Reus VI, Hall SM. Influences of mood, depression history and treatment modality on outcomes in smoking cessation. J Consult Clin Psychol 2004;72:563-70.

48 El-Mohandes AA, El-Khorazaty MN, Kiely M, Gantz MG. Smoking cessation and relapse among pregnant African-American smokers in Washington, DC. Matern Child Health J 2011;15(Suppl. 1):S96-105.

49 El-Mohandes AA, Kiely M, Blake SM, Gantz MG, El-Khorazaty MN. An intervention to reduce environmental tobacco smoke exposure improves pregnancy outcomes. Pediatrics 2010;125:721-8.

50 Flach C, Leese M, Heron J, Evans J, Feder G, Sharp D, et al. Antenatal domestic violence, maternal mental health and subsequent child behaviour: a cohort study. BJOG 2011;118:1383-91.

51 Webb R, Wicks S, Dalman C, Pickles A, Appleby L, Mortensen P, et al. Influence of environmental factors in higher risk of sudden infant death syndrome linked with parental mental illness. Arch Gen Psychiatry 2010;67:69-77. 